\title{
HISTOLOGY OF MENISCO-FEMORAL LIGAMENT
}

\author{
Ghalawat N, Rathee S.K. \\ Department of Anatomy, Pt. B.D.Sharma Post Graduate Institute of Medical Sciences Rohtak, \\ India.
}

\section{ABSTRACT}

Introduction: The menisco-femoral ligament is one of the most important accessory ligament of the knee joint. This ligament acts in synergy with the cruciate ligament. It is important to have the knowledge of this ligament in arthroscopic surgeries. On MRI examination this ligament can be mistaken for osteochondral and meniscal fragment.

Materials and Methods: The present study was carried out on 50 knee joints in two age groups ranging from 2040 years and $41-60$ years in which the histology of this ligament was observed.

Results: Regular dense parallel collagen fibers were seen in the histology of menisco-femoral ligament.

Conclusion: No changes were seen in the histology of ligament with increasing age in the present study with two age groups.

KEY WORDS: Knee Joint, Menisco-Femoral Ligament, Collagen Fibres, Meniscus.

Address for Correspondence: Dr. Neeru Ghalawat, Department Of Anatomy, Pt. B.D.Sharma Post Graduate Institute of Medical Sciences Rohtak, India.

E-Mail:drneeru465@gmail.com

\section{Access this Article online}

\section{Quick Response code}

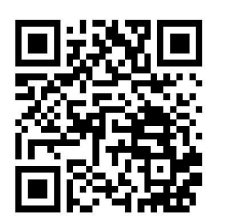

DOI: $10.16965 /$ ijar.2017.195

Web site: International Journal of Anatomy and Research

ISSN 2321-4287

www.ijmhr.org/ijar.htm

Received: 21 Mar 2017

Peer Review: 21 Mar 2017

Revised: None
Accepted: 25 Apr 2017

Published (O): 31 May 2017

Published (P): 31 May 2017

\section{INTRODUCTION}

Menisco-femoral ligament was first discovered by Poirier and Charpy but defined it as third cruciate ligament (cited by Heller and Langman $)^{1}$. Hadjisselimovitch classified this accessory ligament as anterior menisco-femoral ligament attached on anterior horn of lateral meniscus (cited by Heller and Langman) [1]. Kaplan wrote of lateral menisco-femoral ligament having an anterior and posterior part [2]. Menisco-femoral ligament is one of the most important accessory ligament of the knee. It connects the fibro-cartilaginous menisci of the knee to the intercondylar area of femur. Meniscofemoral ligaments are two ligaments that connect posterior horn of lateral meniscus to the lateral aspect of medial femoral condyle. One of these passes anterior to the posterior cruciate ligament and is known as ligament of Humphry or anterior menisco-femoral ligament. It is closely related to the anterior surface of the posterior cruciate ligament. It is never larger than one third of the diameter of adjacent cruciate ligament. The attachment of the anterior menisco-femoral ligament cannot be seen from front. When tibia is rotated medially on the femur the posterior horn of lateral meniscus can be seen and attachment of anterior meniscofemoral ligament can be visualized posteriorly. The other ligament passes posterior to posterior cruciate ligament and is known as ligament of Wrisberg or posterior menisco-femoral 
ligament. This ligament is a distinct structure continuous with posterior horn of the lateral meniscus. As fatty tissue is abundant in this area, it is necessary to trace any band of fibrous tissue to make sure that ligament is in fact the posterior menisco-femoral ligament $[3,4]$.

Baek et al examined four young human cadaveric knees using transmission electron microscopy and reported this ligament to be made up of collagen fibrils. He examined ultra structural anatomy of this ligament. Samples were harvested from proximal, middle and distal region of this ligament. Fibrils of middle region were reported to be larger than those of proximal region [5]. Candiollo and Gautero reported larger diameter of posterior menisco-femoral ligament than anterior menisco-femoral ligament and these ligaments were mainly composed of collagen fibres [6].

Gupte et al reported the neural structure in menisco-femoral ligament near its meniscal attachment. They had an important role in propioception and in providing a neurosensory feedback loop [7].

Stoller et al reported these ligaments as a straight band of collagen fibres [8].

\section{MATERIALS AND METHODS}

The present study was conducted in the department of Anatomy at Pt. B.D.Sharma Post Graduate Institute of Medical Sciences Rohtak. The proposed study was carried out on 50 knee joints in two age groups ranging from 20-40 years and 41-60 years in the department of Anatomy on the human cadaveric knee joint.

\section{Exclusion criteria:}

Following cases were excluded from study: Cadavers in which any obvious traumatic injury to the knee joint, cadavers in which knee joint were distorted, cadavers with any surgical scar marks on the knee joint.

The anterior menisco-femoral ligament is posterior to anterior cruciate ligament and anterior to the posterior cruciate ligament so it could be visualized only when the knee joint is exposed from anterior aspect. The posterior menisco-femoral ligament is posterior to the posterior cruciate ligament and hence could be visualized best when knee joint is exposed from posterior aspect After dissection following parameters were measured the direction of fibers of MFL was noted.

Histological Examination: A piece of meniscofemoral ligament was taken and then immersed into fixative. The tissue was fixed in $10 \%$ formalin for 24 hours in a container which was numbered as on the specimen. After the tissue was fixed, then water was removed from the fixed specimen by passing it through a series of ascending grade of alcohols that is from $70 \%$ to $100 \%$. Then the specimen was cleared of alcohol by passing it through several changes of clearing agent. Xylene was used as clearing agent, which is miscible with both alcohol and paraffin.

Once the specimen was impregnated with clearing agent xylene, it was then placed in warm mold containing melted paraffin. Once removed from the heat source, paraffin in the mould cooled, solidified and encased the specimen. Block was then trimmed to a size of specimen and mounted on an instrument called microtome. Then section were cut at specific and predetermined increments with a steel knife. Sections of seven micron thickness were cut. These sections were placed on a glass slide that was covered with a thin layer of albumen, which served as an adhesive medium for specimen. To stain the specimen in section paraffin was dissolved with solvent xylene. Then sections were rehydrated with a series of decreasing alcohol concentration. These hydrated sections were then stained with water soluble stain hematoxyline and eosin. Five sections were used from each block. Five random fields were studied from each slide. Direction of fibers in each section of tissue of ligament was confirmed.

\section{RESULTS}

Histology: Regular dense parallel collagen fibers were seen. Between collagen fibers loose connective tissue was observed. Fibroblasts were seen between collagen fibers. These findings were observed in all the sections studied. 
Fig. 1: Showing collagenous bundle in menisco-femoral ligament.

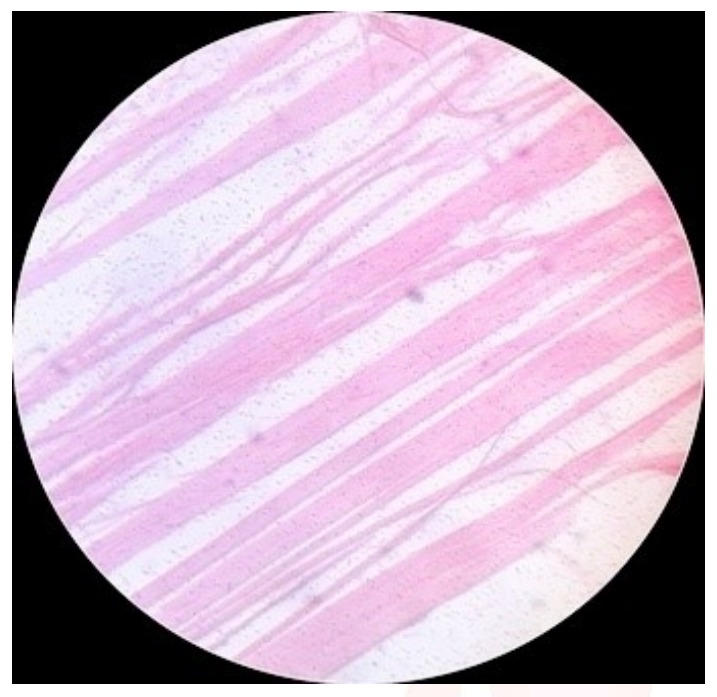

\section{DISCUSSION}

Knee joint is one of the most important joint of our body. It has an important role in carrying body weight and in walking, running and jumping. Large numbers of ligaments are present in relation with knee joint. Menisco-femoral ligament is one of the most important accessory ligaments of the knee. It extends from the posterior horn of lateral meniscus to the lateral aspect of medial femoral condyle close to the femoral attachment of the posterior cruciate ligament.

Vast amount of literature is available regarding this ligament. Review of literature reveals no unanimity of opinion. This ligament is significant biomechanical structure in the knee joint because of its size and strength and it has protective influence on the posterior horn of lateral meniscus [9].

Baek et al examined ultrastructural anatomy of this ligament and reported this ligament to be made up of collagen fibrils [6]. Candiollo et al and Stoller et al also reported these ligaments to be made up of collagen fibres [10].

All these findings were in accordance to the present study which also stated these ligaments to be comprised of collagenous bundle.

\section{CONCLUSION}

No changes were seen in the histology of ligament with increasing age, in the present study between two age groups.

\section{Conflicts of Interests: None}

\section{REFERENCES}

[1]. Heller L, Langman J. The menisco-femoral ligaments of the human knee. J Bone Joint Surg. 1964;46B:307-13.

[2]. Kaplan EB. The lateral meniscofemoral ligament of the knee joint. Bull Hosp Dis. 1956;17:176-82.

[3]. Yamamoto M, Hirohata K. Anatomical study on the menisco-femoral ligaments of the knee. Kobe J Med Sci. 1991;37:209-26.

[4]. Felle $P$, Wan AC. The menisco-femoral ligaments. Clin Anat. 1995;8(5):323-6.

[5]. Baek GH, Carlin GJ, Vorgin TM, Woo SLY, Harner CD. Quantative analysis of collagen fibrils of human cruciate and menisci-femoral ligaments. Clin Orth and Rel Res. 1998;357:205-11.

[6]. Candiollo L, Gautero G. Morphologie et fonction des ligaments ménisco-femoraux de l'articulation de genou chez l'homme. Acta Ana. 1959;38:304-23.

[7]. Gupte CM, Bull AMJ, Thomas RD, Amis AA. A Review of the function and biomechanics of the meniscofemoral ligaments. Arthro. 2003;11:271281.

[8]. Stoller DW, Anderson LJ, Cannon WD. Magnetic resonance imaging. Ortho and Sports Med. The Knee, Lippincott Williams \& Wilkins; Baltimore; $3^{\text {rd }}$ ed. 2007.p.450.

[9]. Poynton AR, Javadpour SM, Finegan PJ, Brien M. The menisco-femoral ligament of the knee. J Bone Joint Surg. 1997;79B(2):327-30.

[10]. Merida-Velasco JA, Sanchez-Montensinos I, Espin Ferra J, Merida-Velasco JR, Development of the human knee joint ligaments. The Anat Rec. 1997;248:259-68.

[11]. Gupte CM, Smith A, Jamieson N, Bull AMJ, Amis AA. Meniscofemoral ligaments structural and material properties. Journal of Biomechanics 2002;35:162329.

How to cite this article:

Ghalawat N, Rathee S.K. HISTOLOGY OF MENISCO-FEMORAL LIGAMENT. Int J Anat Res 2017;5(2.2):3833-3835. DOI: 10.16965/ ijar.2017.195 